\title{
Interior Design and Decoration; From Attention to Distinction
}

\section{Dr.AbdulmounimTaha Ali}

\author{
Ajman University \\ College of Engineering \\ Department of Interior Design \\ Ajman/ United Arab Emirates
}




\title{
$\underline{\text { Interior Design and Decoration; }}$
}

\section{From Attention to Distinction}

\author{
AbdulmounimTaha Ali \\ Ajman University of Science \& Technology \\ College of Engineering/ Department of Interior Design
}

\begin{abstract}
$\underline{\text { Abstract }}$
The distinction or uniqueness means a way of explanting the inner personality of an individual or a certain environmental society together with their interests. This way of explanation has resulted from the development of different aspects of features and techniques throughout the centuries.

Interior design, along with its elements and components, are considered as one of the environmental features. These features point out the degree and positional status of individuals as well as groups or societies in general. This happens with regard to economy, behaviors, ambitions anddesire toward uniqueness as well.
\end{abstract}

\section{Intoduction:}

First of all, aiming at considering the title of this study while adopting a sensible approach, which combines integrity with knowledge, each of the two terms: "Design" \& "Decoration", must be provided with a definitional concept in order to enable the launch of a process of analysis, explanation and clarification. This shall lead to create a scientific text, which, in turn, shall help us to set cognitive, social and humane judgmentsand, sometimes, other judgments of a behavioral and personal dimension related to the human being as an individual or as a member of his/her community.

Concerning the meaning and notion of the term: تصميح- (Design) in Arabic, it is derived from the trilateral verb: صمم, which means to decide to do and put something into practice and even complete it. Undoubtedly, thismeaning shall lead to a cognitive issue, which signifies that such resolution or action needs pre- conception and preconsideration.

As for the term: "Decoration", it means ornamentation andproviding the highest possible amount of characteristics in order to reflect the features, interests and 
aspiration planted in thehuman nature through aesthetic symbols or properties represented bymaterial patterns orconfigurations.

Various examples, which have been developed throughout history, can provide an explanation of such trend. Such phenomena, which crystalize such interest and uniqueness, commenced with the archaic humans. This can be traced back in the paintings on the internal walls of caves, in covering parts of the human body with tattoos orin constructing various architectural configurationsalong with their interior designs of distinctive properties in terms of their figure, method of implementation or use and utilization of ores, elements and ornamental supplements of special, innovative or different nature from what is common or even conventional specifications. All of the aforementioned phenomena or factors were launched as a reflection of possibilities and special abilities that result in uniqueness and distinction. They have endured through the years as phenomena, expressing the real image, identity and special interests as well as the features, nature and elements of the surrounding environment and community. Accordingly, the modern function of interior design is complicated and has multi-implications while requiring scientific and practical skills in order to be impressive, meet the architectural and environmental needs and reflect creative and distinctive abilities through various approaches and methods depending on the personal interests as well as cultural and economic background (Lawson, p 11).

\section{The Research Issue:}

Following the economic, cultural and technological development side by side with openness to the world, it became far moreeasier to express admiration, acquire and receive the impacts of modern and various propertiessince individuals or communities became more interested in interiordesign anddecoration along with its distinguished characteristics regarding them as elements that reflect uniqueness and distinction. Hence, such concernhas gradually controlled elements, such as aesthetic or sensational willingness, taste or awareness, at the expense of other features like the essence and environmental, social and traditional heritage. Most of the configurative elements as well as the prerequisites utilized in execution enjoy no real relationship derived from the individual's identity, background or even actual necessity. Thus, individuals are now being surrounded by foreign and unfamiliar elementswhich, when acquired,grant them distinctiveness. Needless to say, that this shall be at the expense of real satisfaction and closeness as well as the bond which combines the relevant individual with the subject matter element.

\section{Target of the Research:}

Some people approaches interior design and decoration on the basis that they are merely a comprehensive process of selecting elements, colors and ornamental supplements together with organizing and allocating pieces of furniture. However, as a matter of fact, interior design and decoration must also concentrate on, and reflect, issues and elements related to the surrounding environment along with nature and properties of the relevant architectural configuration as well as comprehensive awareness of the beneficiary's cultural and socio-economic background and personal interests that reflect the identity and intimate entity. 
Seeking to acquaint with the true meaning of such prerequisites and put them into practice based on the relevant standards and methods, we need to adhere to clarity, and scientific professionalism in order to consider, analyze and select the elements, which compose and complement the design, and utilize them as per the details of the practical and scientific plans, which are implemented through preparing detailed shop drawings, enabling of crystalizing the final vision of aninterior design and decoration,meeting the relevant necessities, satisfying the interests and reflecting eagerness to parade and acquire distinguished properties of a special nature.

What is Distinction, or Uniqueness, to us? What is its Influence on the Human nature?

Uniqueness- or distinction or showing off- represents a state that can be explained by a number of philosophical, psychological, sociological, biological and socioeconomic factors, and it plays the role of a motivation, which prompts the human being to explore his/her subjective abilities (Kilmer, p. 21) in order to prove and express oneself in a specific time, place or case, which the other person, namely the rival, does not enjoy in the same period.

Such state has accompanied the human being evolution since their very beginningsand has, through different ages, assumed various tendencies and directions in accordance with the coincident alterations and changes as well as the socioeconomic constants prevalent in the relevant community. Besides, the human being has considered them on equal basis with his conventional constants exploited in his confrontations and conflicts of survival represented by proving the well-known saying: the strongest shall survivebut in more sophisticated manner as the same saying turns out to be: the well-versed and skilled shall be the unique".

Throughout the various ages, with different deliverables and abilities, based on his/her inner and unique affections, the individual has always been fond of a halo that outlined his/her aspiration towards boasting and excellence and, besides, such interests has taken on multiple tendencies and various approaches. Every individual, whether a woman or a man, should be pleased and spiritually satisfied if she/he became famous or she/he became distinguished with some specific matter of weird or lovely features, which her/his peers lack. Such pleasure shall fit the relevant individual with ability and determination to rapidly exceed several stages, which typically require time, costs and hard working.

It is said that the human is natural born selfish but in a positive manner. This is obvious in the persistent endeavor to be distinctive and such distinction or uniqueness is demonstrated in several manners as per the prevailing circumstances while the purpose thereof is to attract hearts and minds. Distinction can be achieved throughbeauty or being described as beautiful, well-versed or having special ability at absorption, tasting, comprehension, cognition or selection or judgment of various deliverables or examples.

Excellence or showing off inherited or acquired abilities represent a number of the dynamics and real motivations, which urge humans to realize the purpose or achieve the goal in both of its sides, the desired and the unpleasant. Besides, assessment and 
Proc. of The Seventh Intl. Conf. on Advances in Social Science, Management and Human Behaviour - SMHB 2018. Copyright (C) Institute of Research Engineers and Doctors, USA. All rights reserved.

ISBN: 978-1-63248-160-3 doi: 10.15224/978-1-63248-160-3-30

ability to control inherited or acquired powers require rationality and awareness of managing such unleashed wild abilities in order to achieve the positive objective of such uniqueness or distinction.

Moreover, in different aspects of life, we face persistent conflicting and running (in both positive and negative sides) on realizing the purpose represented in distinction or showing off. The real essence, features and behavior of the individual became internal characteristics, which are often very hard to be recognized since the excellence halo along with its explicit symbols are being the required expressive and impressiveoutward image.

Accordingly, a number of people seek to produce some representations of themselvesor some reflections of themselves in many fields, including in interior design and decoration field, which demonstrate their physical or moral appropriation in various aspects. Thus, interior design and decoration are being exploited as figures, which attract admiration and reflect traits, special interests, ego and aspirationsin unique forms, methods and patterns of preparation, acquirement and execution (Figures $1 \& 2$ ).

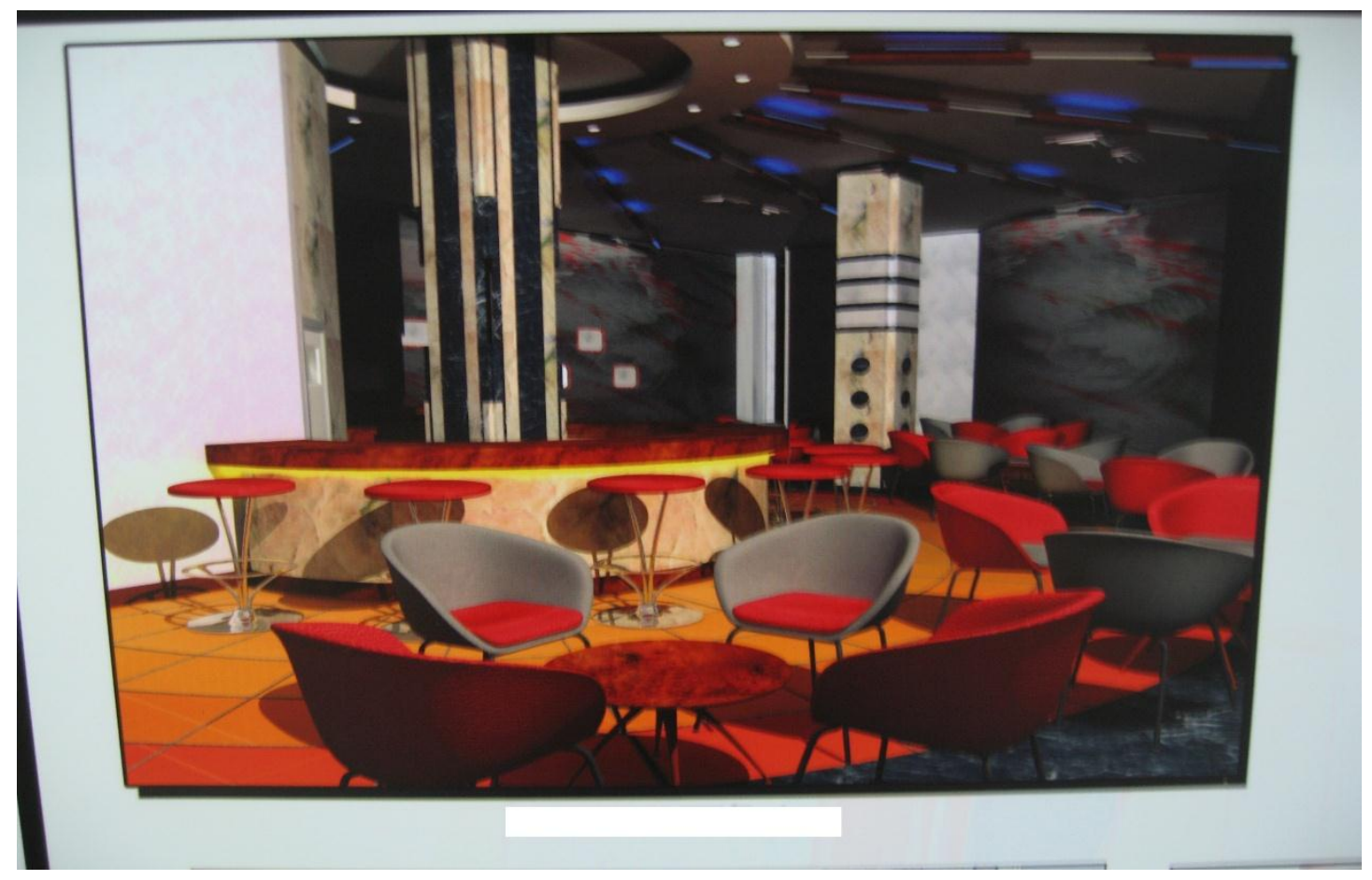

(Figure 1) 


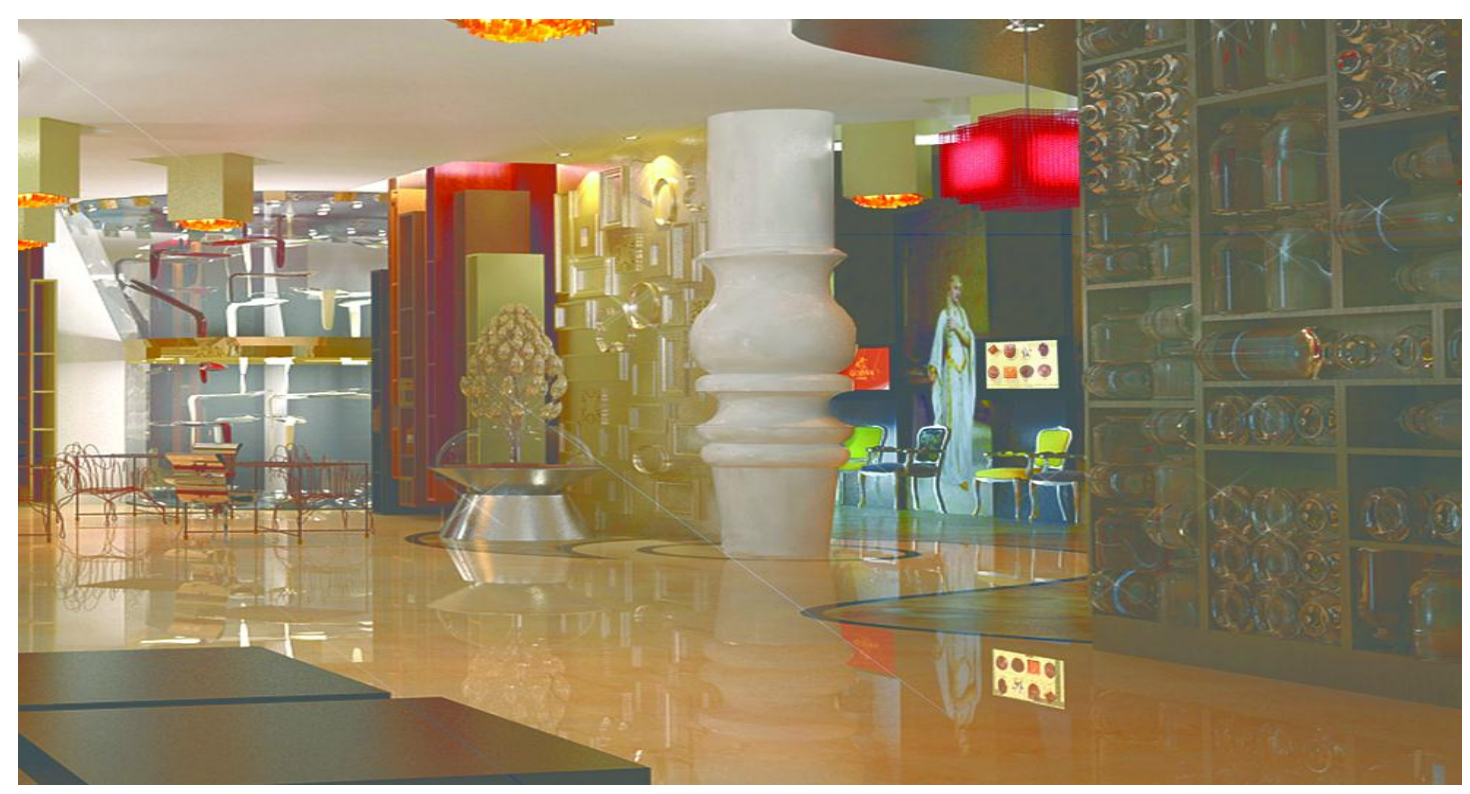

(Figure 2)

(Figures 1\&2) Illustrative drawings reflecting the modern and special methods of configuration

(the author's archive)

\section{Historical Examples of Uniqueness orExcellence in Architectural Design \& Interior Decoration:}

Throughout the various historical ages, humans have attempted to produce a large number of monuments and features, which reflect interests, beliefs and ability to challenge, create and express in several methods and approaches; some are vivid while the others are fairly ambiguous in terms of vision and execution. However, in both cases, the attempt was concentrated on attaining the vision as well as the special feelings based on an innovative, expressive and configurative approach, which reflects the need to explore the essence and subjective abilities as well as the endeavor to appropriate illustrative features through different methods in terms of patterns and senses.

Paintings and ornaments carved on the internal walls of the archaic human's caves are proper examples of distinguished implications, reflecting thoughts, beliefs, feelings and interests. (Figure 3) (Whiton, Abercrombie, p. 5). 


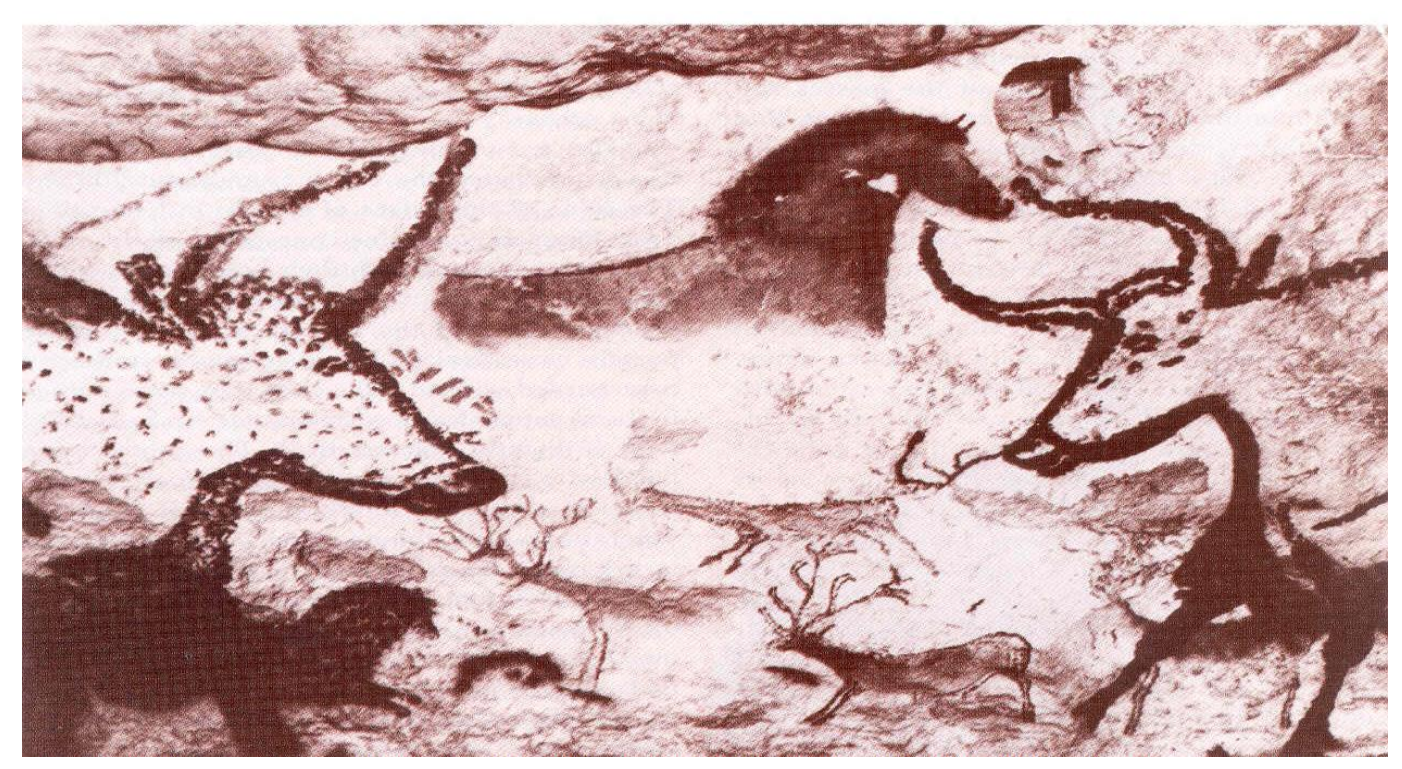

Figure (3)

An illustrative figure representing the reflection of the ego and feelings by the caveman.

Furthermore, this distinction or uniqueness was also demonstratedin different approaches in the graphic features and ornamental architecture of the Pharaohs, whose vision and interest in uniqueness are crystalized in symbols and distinctive figures in their architectural designs through unique configurations in the architectural patterns, such as the Great Mosque of Samarra (Figure 4) (https://www.britannica.com/list/8masterpieces-of-islamic-architecture), the pyramids and tombs as well as the ornamental arts and furniture industry, which have stood thousands of years, representing their vision and constituting a magnificent example of their civilization. (Figure 5 \& 6) (Whiton, Abercrombie, p. 14, 26). 
Proc. of The Seventh Intl. Conf. on Advances in Social Science, Management and Human Behaviour - SMHB 2018. Copyright (C) Institute of Research Engineers and Doctors, USA. All rights reserved.

ISBN: 978-1-63248-160-3 doi: 10.15224/978-1-63248-160-3-30

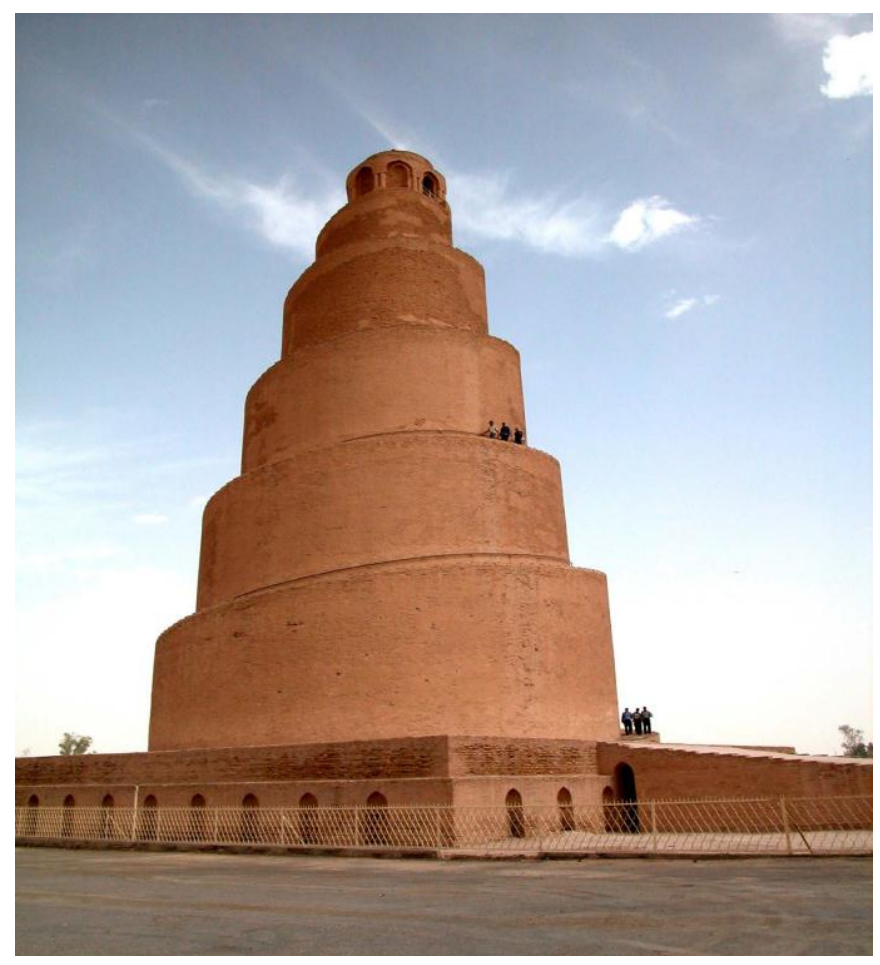

(Figure 4)

\section{Great Mosque of Samarra}

https://www.britannica.com/list/8-masterpieces-of-islamic-architecture

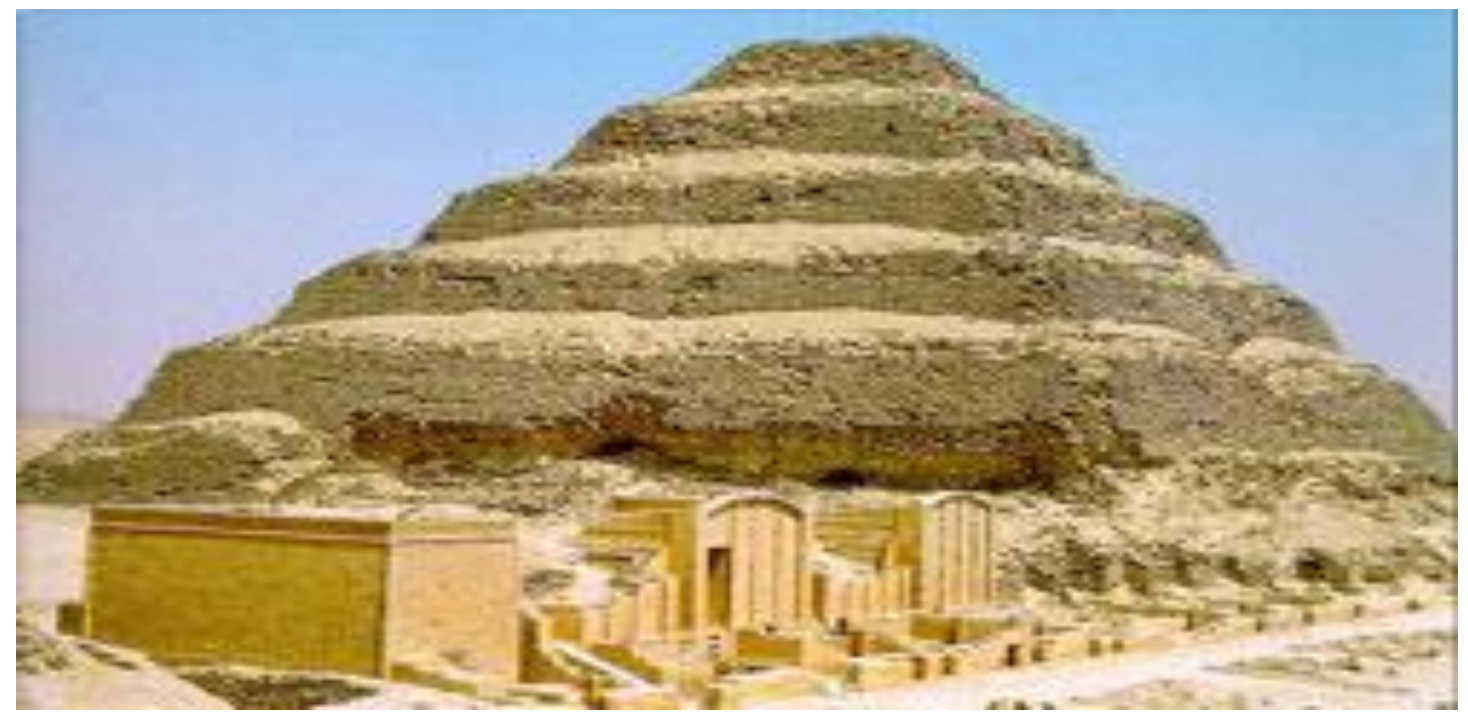

(Figure 5)

An illustrative figure representing uniqueness and excellence in configuration 


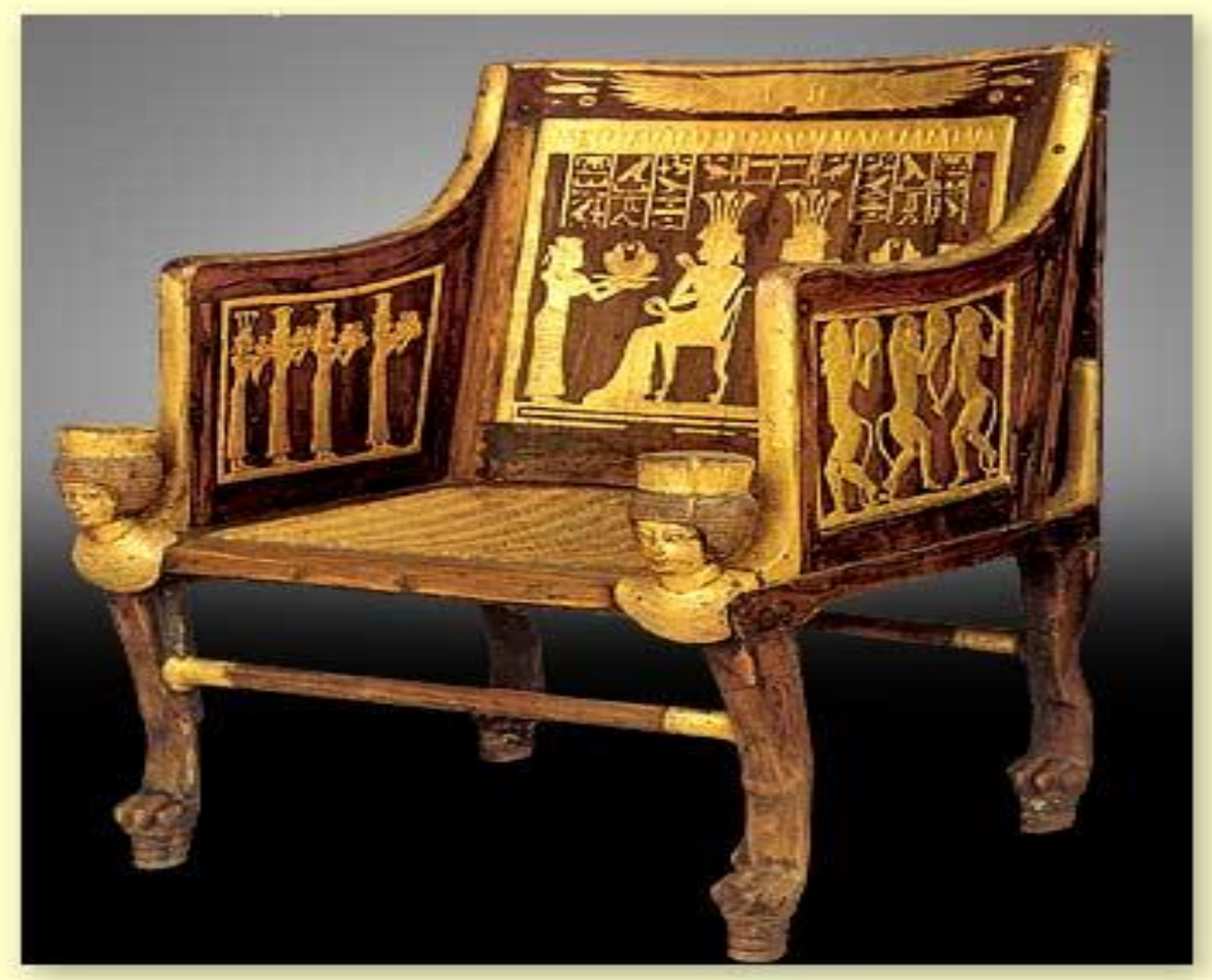

(Figure 6)

A figure demonstrating a piece of furniture (chair) of ornamental features and distinctive impression.

Such expression continued assuming different patterns, phenomena, approaches and techniques as we can see with the Greeks, the Romans and the Byzantines (Figure 7, 8 \& 9) (John Pile, p. 31, 55) who realized high levels of ability to recognize and demonstrate special features in architectural design, arts and design. Such features provided them with the special vision and pattern throughout consecutive generations and civilizations in frequent and revolving manners. Furthermore, uniqueness was demonstrated in the Islamic arts through the configuring designs of the abstract ornamental units as well as a number of architectural configuration elements. (Figure 10 \& 11) (John Pile, p. 69, 75). 
Proc. of The Seventh Intl. Conf. on Advances in Social Science, Management and Human Behaviour - SMHB 2018. Copyright (C) Institute of Research Engineers and Doctors, USA. All rights reserved.

ISBN: 978-1-63248-160-3 doi: 10.15224/978-1-63248-160-3-30

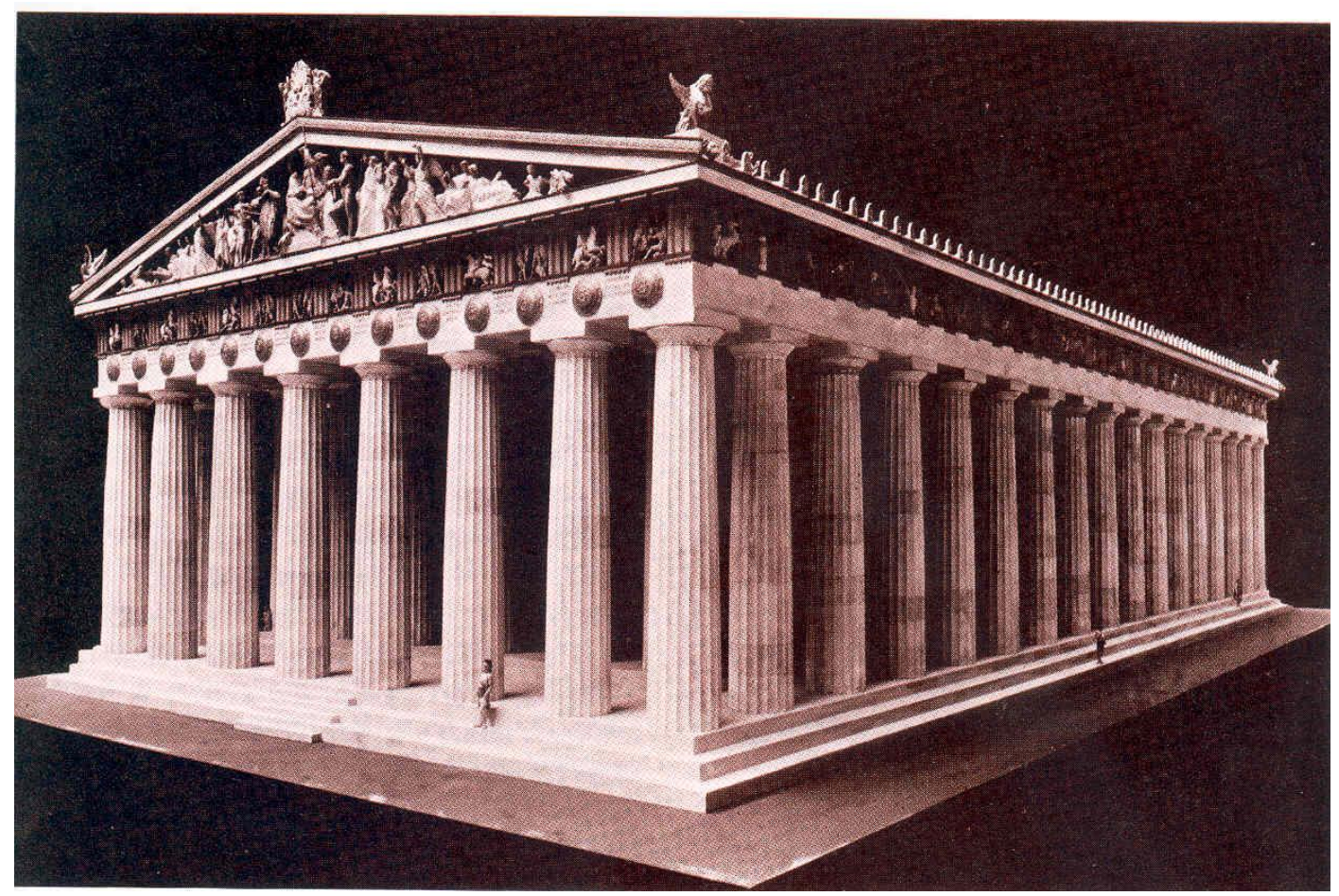

(Figure 7)

A distinctive configuration of a Greek architectural masterpiece (the Parthenon Temple) demonstrating special features expressing uniqueness in utilizing architectural elements and ornamental configurations.

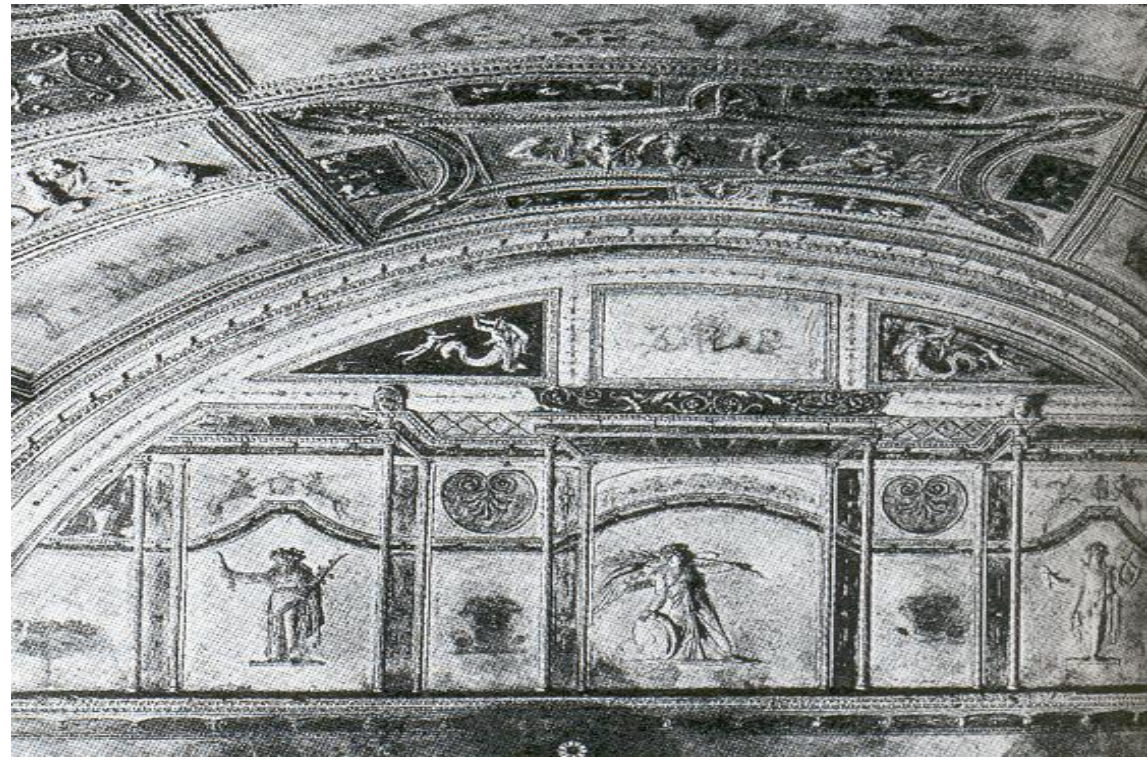

(Figure 8)

Roman Interior murals reflecting prominent configurations and carvings with an interesting aesthetic method expressing the uniqueness of the site as well as the event at the same time. 


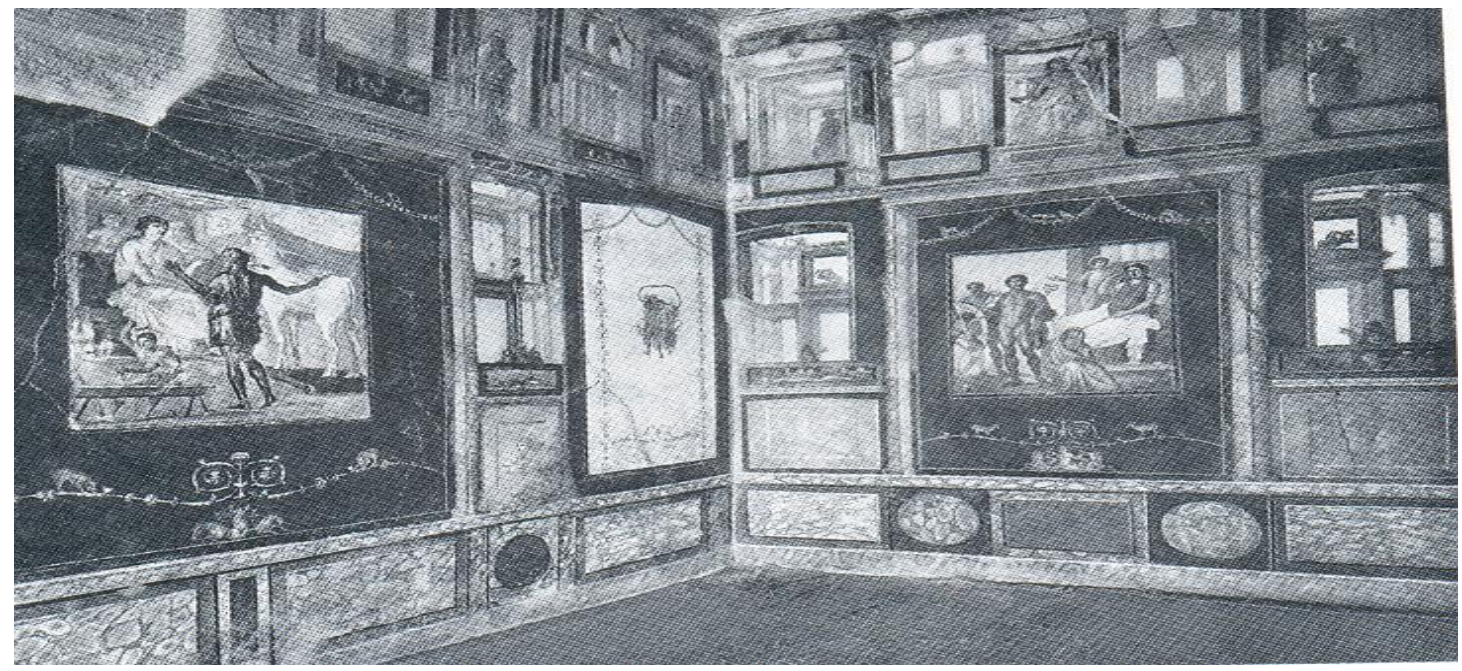

(Figure 9)

Distinguished interior configurations of a Roman building illustrating the features of utilizing drawings within an impressive aesthetic outline, which adds distinctiveness to the spirit of the configurations.

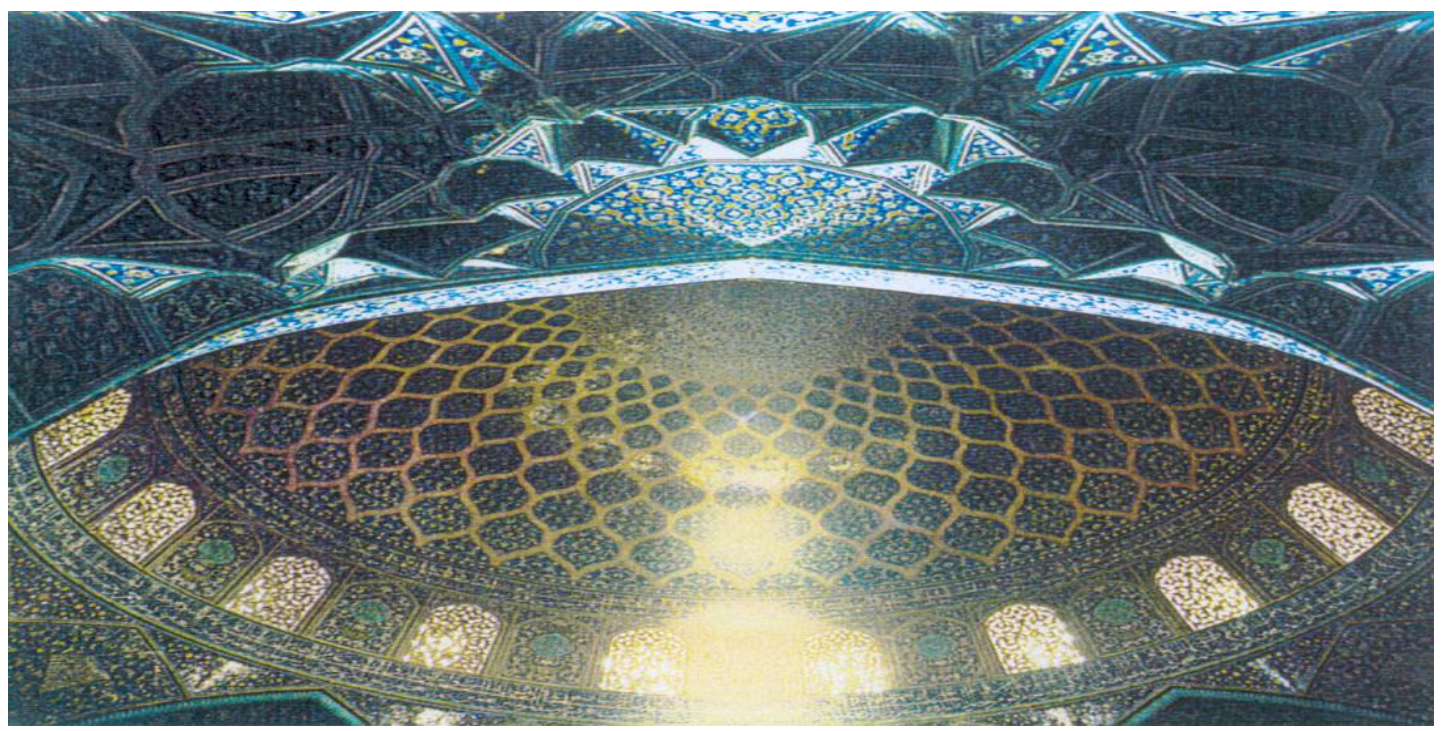

(Figure 10)

Aesthetic \& architectural characteristics of an Islamic interior architectural configuration reflecting the uniqueness of signification and impression. 


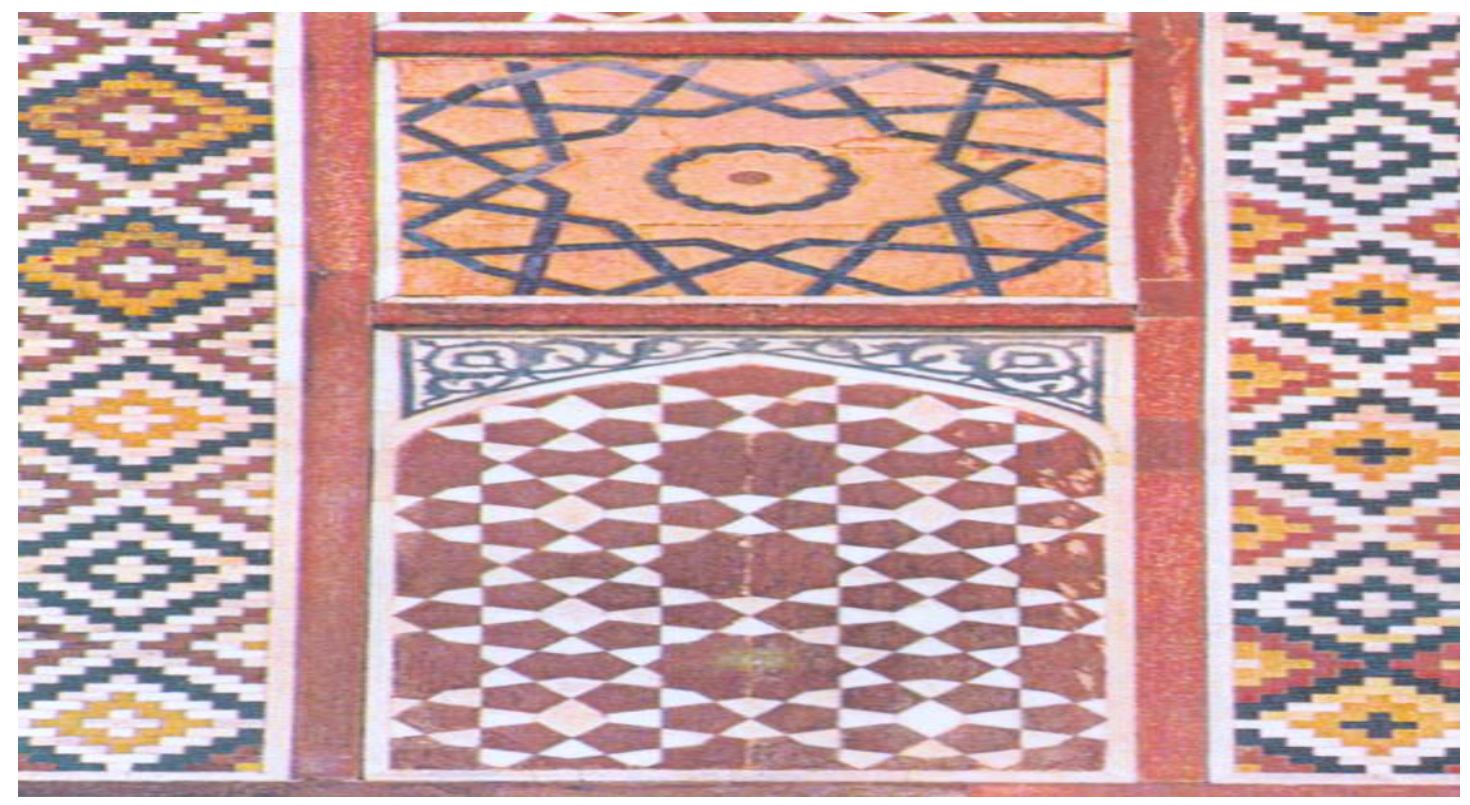

(Figure 11)

Islamic ornamental features of various abstract profiles reflecting the uniqueness of interest as well as the philosophy of configuration.

Throughout centuries, distinctions have been reflected through multiple patterns based on various influences so far today since desire to be excellent or unique has taken on different tendencies and aspects enabled to be crystalized by the cultural, economic and technological progress as well as the spirit of competitiveness and showing off. Hence, new images, patterns and configurations emerged, wherein ores and elements were utilized based on multiple approaches and techniques, some of which may be described as new modes or variant approaches compared to the already existed or conventional ones (Figures $12 \& 13$ ). All of the aforementioned approaches were based on a serious endeavors to be a special expression of a specific individual, community, country or civilization or an explanation for a vision or a philosophy based on a specific approach and technique (Figure 14). 
Proc. of The Seventh Intl. Conf. on Advances in Social Science, Management and Human Behaviour - SMHB 2018.

Copyright (C) Institute of Research Engineers and Doctors, USA. All rights reserved.

ISBN: 978-1-63248-160-3 doi: 10.15224/978-1-63248-160-3-30

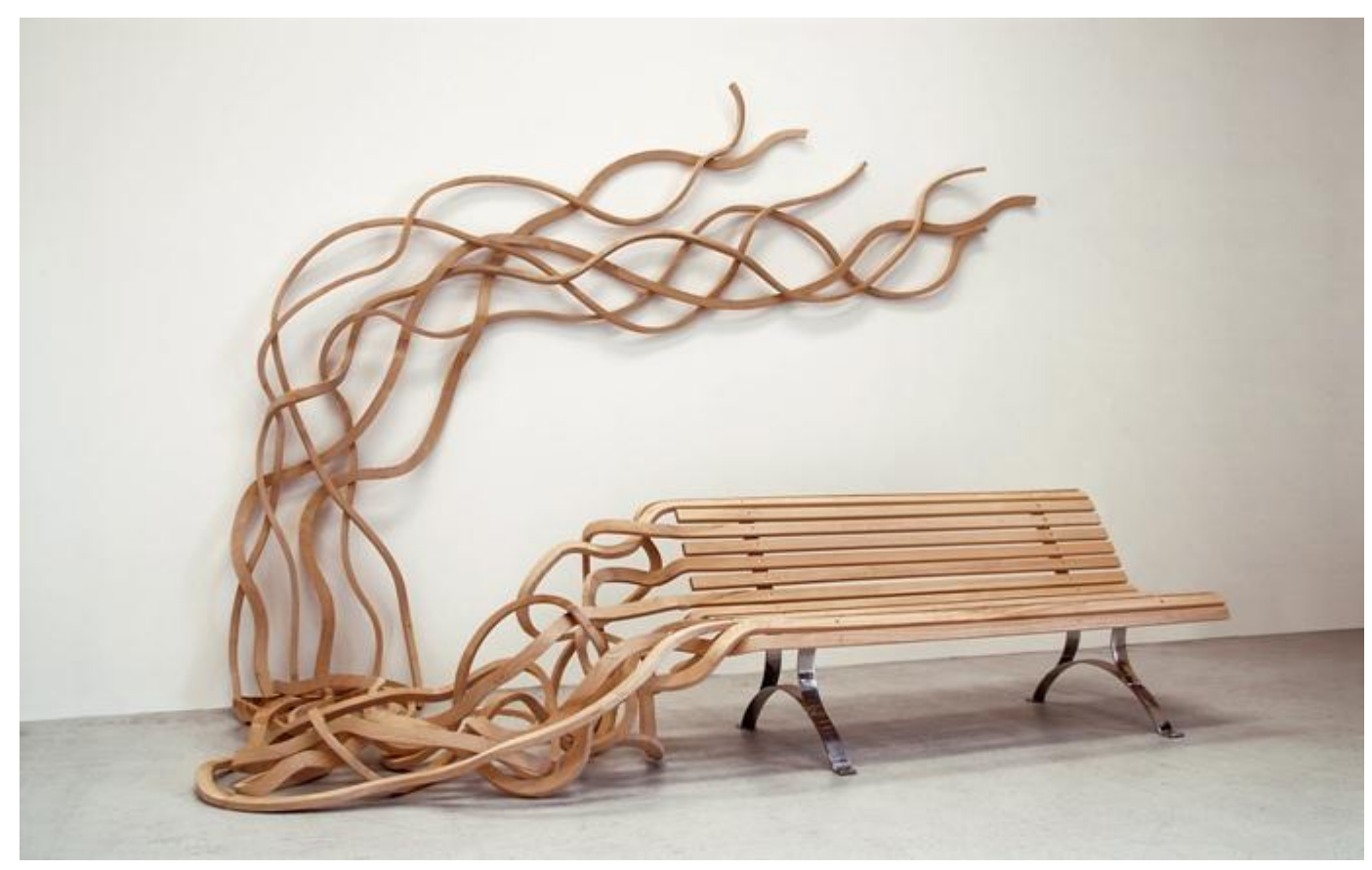

(Figure 12)

\section{THE ORANGE WOOD BENCH}

A configuration of a piece of furniture executed based on a distinctive and weird approach, representing new modes in configuration.

HTTPS: HOMESTHETICS.NET/40-OF-THE-MOST UNUSUAL-AND-BIZARRE-FURNITUREDESIGNS-YOU-HAVE-EVER-SEEN/

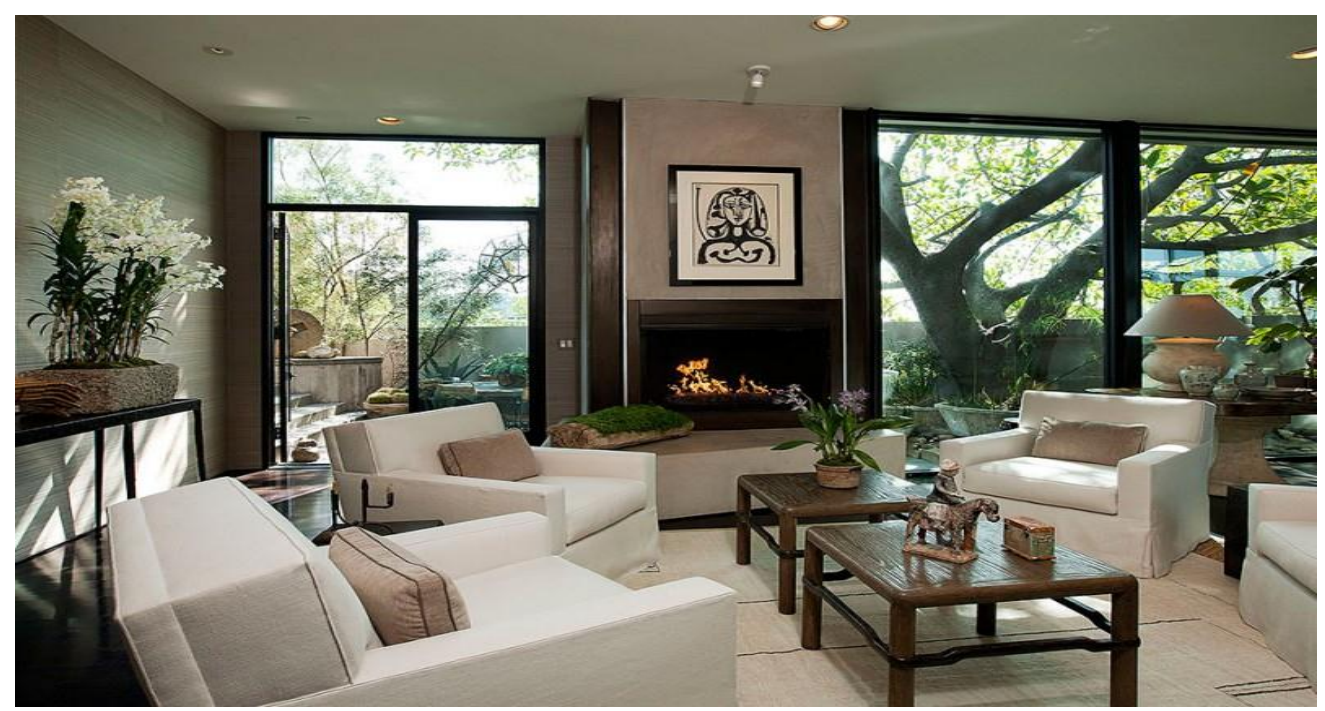

(Figure 13)

An interior configuration of elements executed in a distinguished approach, combining contemporariness with modernism

https://www.homedsgn.com/2012/09/02/contemporary-meets-traditional-on-sunset-strip/ 


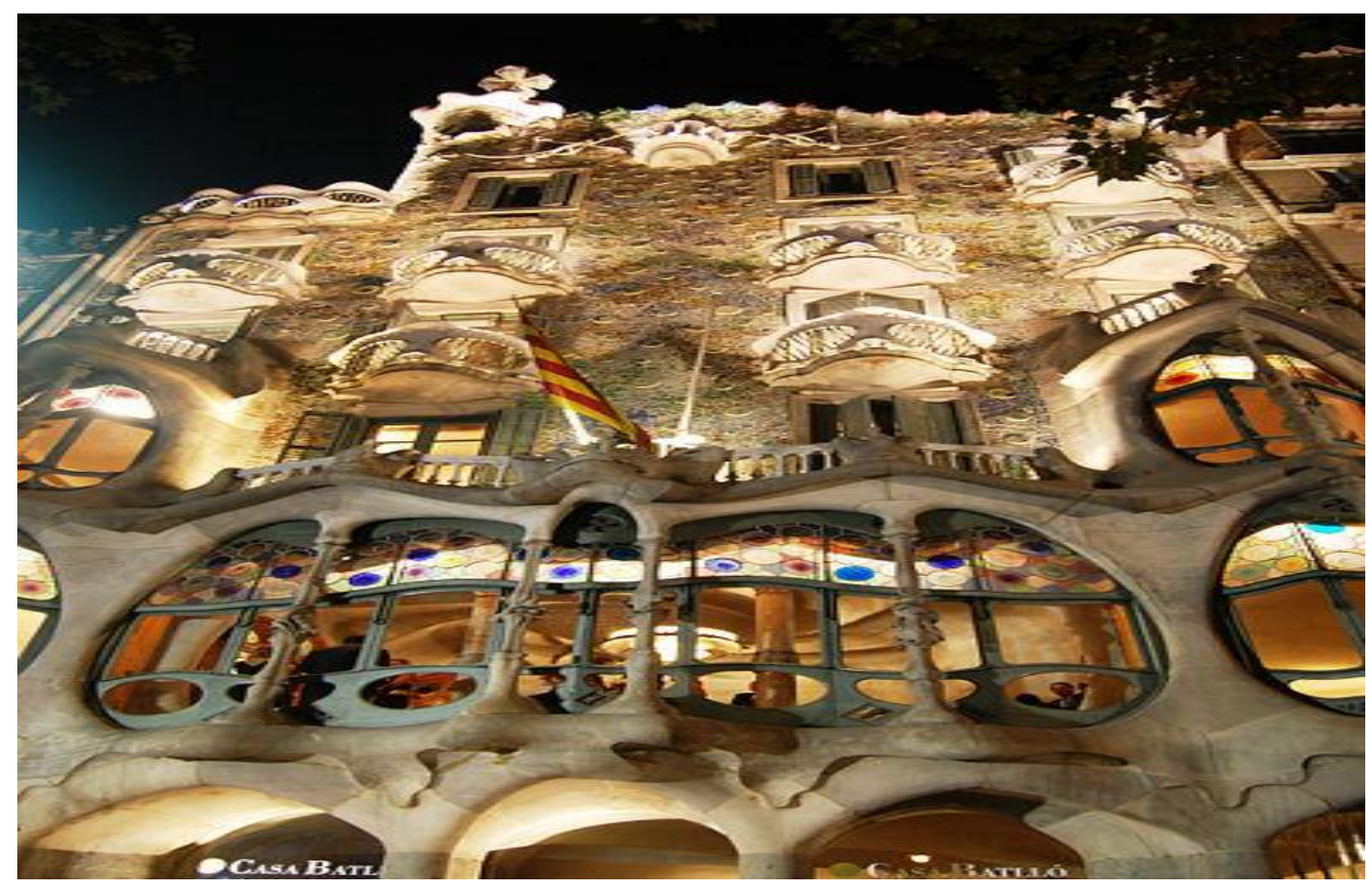

(Figure 14)

A figure representing a contemporary architectural configuration executed in an approach expressing the philosophy of the vision and configuration.

https://www.google.ae/search?safe=strict\&sa=X\&q=Casa+Batlló\&stick=H4sIAAAAAAA AAG1Ru3LTQBRFBZCszUwQkyGoYDKp6CytrFdJAsN4JnGAhFqglSxZ-5DXWiS

\section{Elements of Excellence in Interior Design \& Decoration:}

Interior design and decoration are defined as planning and creativeness as per the conditions, which represent wide cognition and awareness of all architectural matters and aesthetic standards, through which specific architectural deliverables and features are crystalized while concentrating on processing and setting proper solutions by exploiting different materials, colors and fittings related to furniture and the method of selecting and utilizing them in the proper places as well as paying attention to other coordination matters, such as lighting and accessories, distributing them and setting an objective for such planning or configuration represented by seeking to produce a sense of comfortableness and joy through meeting the actual need of individual, society and environment based on all of its sides, material, mental, aesthetic and functional (Nielson, p. 21).

Accordingly, the function of interior design and decoration is not confined onlyto paying attention to configuring examples, material or moral satisfaction thereof, enjoying, and being impressed by, the aestheticism of the patterns or the elements of configuration therein, from selecting the colors to the type of harmonization and method of distributing the pieces of furniture, but it also assumes other dimensions related to rendering and exploiting elements and inputs of public and private interest, 
integrating them into the other material and moral elements of design (Piotrowski, p. 2) and imposing a spirit or vision derived from all of such elements in a distinctive approach or configuration, signifying a special acquirement or an individual rendering of a specific necessity, representing and expressing the essence and necessity through producing the real notion of the cultural and socio-economic background as well as the belief and attention since comfortableness or satisfaction towards design is derived from two pivots- while the first is related to the psychological side, the other is represented by the mental one (OtlAicher, p.p. 14-15).

Thus, based on all the elements of their configuration, the interior design and decoration accurately reflect all of the subjective features, the environmental elements and the requirements of the architectural rules, regulations and categories in a distinctive approach through processing the ores constituting the interior design and creatively exploiting them in coincidence with the relevant need, deliverables and environmental and subjective factors (Alderman, p. XI).

\section{Conclusion:}

Work and creativity are two inherent elements of any human being as a human always seeks, based on such two elements, to respond to all life deliverables aiming at enhancing his status and social and environmental position. Paying attention to distinction or uniqueness is one of such human deliverables or concerns, which were rendered into various notions and facts in different life and environmental spheres, helping humans to satisfy their willingness and subjective interests and providing them with a scale for measuring the level of influence of their positions in society.

Distinction or uniqueness in interior design and decoration, namely one of the human concerns which reflected and crystalized configurative features through a creative or different approach compared to the surrounding configurations or examples. Humans are natural born aspirant to be the best or to be distinctive since they know, and are interested in, the new. Besides, theyinteract the new and exploit it along with other factors and motivations in order to achieve an integrated notion, which reflects them as individuals living in communities of specific environment enjoying its own cultural and socio-economic entity, features and structure.

The process of distinction commences from the early stages of preparing the concept suggested for configuration, determining and setting the characteristics or features and distributing them in the relevant detailed plansandutilizing and exploiting the required aesthetic elements and supplements of creative or new features, through which the pattern or structure of configuration is crystalized and which are described as being distinctive, or they are actually distinctive, compared with the surrounding environment. Such distinctive vision produces uniqueness since it may be said that if one is willing to attract attention, one must be distinctive. The necessity, willingness realization and interests are met through the features of distinctiveness in various human deliverables, including interior design and decoration, since distinctiveness is the efficient factor of marketing and attracting admiration. 


\section{Recommendations:}

Researcher recommends as follows;

- To bolster the initial relationship between comprehension and practice in exploiting and utilizing the factors of interior design and decoration and the philosophy of uniqueness or distinction, which keep up with the necessity and attention requirements.

- To concentrate on scientific and technological expansion in the spheres and curricula related to innovation or excellence in colleges or institutions, which teach interior design and decoration, in order to enhance the graduates' comprehension and awareness of the significance of such curricula when dealing with the beneficiary.

- To stay up-to-date regarding the technological development in preparation and application, to improve the interior designer's cognition and awareness in order to reach the models capable of achieving creativity and excellence.

- To realize a common structure among specialists and researchers in the fields of interior design and decoration in order to achieve models capable ofproducing design configurations of distinctive or unique nature, which keep up with the coincident possibilities and requirements.

- To establish professional and empirical institutions in order to concentrate on the elements of distinctive and creative nature and to allocate staff trained on utilizing sophisticated technologies in order to exploit such technologies.

- To recourse to specialists interested in the nature and features of the elements of distinction or uniqueness in interior design and decoration as well as the method of exploiting them in order to explicitly determine their efficiency and effects in the internal architectural configurations.

- To continue studies and scientific and applying researches by specialized designers interested in the features of interior design and decoration in order to determine the features of innovation, distinction and the proper methods of application to satisfy the requirements as well as necessities. 
Proc. of The Seventh Intl. Conf. on Advances in Social Science, Management and Human Behaviour - SMHB 2018. Copyright (C) Institute of Research Engineers and Doctors, USA. All rights reserved. ISBN: 978-1-63248-160-3 doi: 10.15224/978-1-63248-160-3-30

\section{$\underline{\text { References }}$}

- Bryan Lawson (1997), How Designers Think, Biddles, Ltd, UK

- Christine Piotrowski (2004), Becoming an Interior Designer, John Wiley \& Sons, Inc., USA, N.J.

- John Pile ( 2005), A history of Interior Design, Laurence King Publishing Ltd, UK

- Karia j. Nielson (2007), An Important of the Interiors, MCGRAW-HILL companies, USA, N. Y.

- OtlAicher( 1994), The World as Design , Ernst \&Sohn, Berlin

- Robert L. Alderman (1997), How to Prosper as an Interior Designer, John Wiley \& Sons, Inc., USA,N.Y

- Rosemary Kilmer, W. Otie Kilmer (1992), Designing Interiors, Thomson Learning, Inc., USA.

- Sherrill Whiton, Stanley Abercrombie (2002), Interior Design and Decoration, Pearson Education, Inc., USA, N.J.

- https://www.homedsgn.com/2012/09/02/contemporary-meets-traditional-on-sunsetstrip/

- https://www.google.ae/search?safe=strict\&sa=X\&q=Casa+Batlló\&stick=H4sIAAAAA AAAAG1Ru3LTQBRFBZCszUwQkyGoYDKp6CytrFdJAsN4JnGAhFqglSxZ5DXWiS 